\title{
Cardiovascular protection with candesartan in patients with metabolic disorders
}

\author{
Hypertension Research (2010) 33, 1312-1313; doi:10.1038/hr.2010.128; published online 22 July 2010
}

We read with interest the paper of Nakao et al. ${ }^{1}$ about the role of pre-existing diabetes or obesity in the Candesartan Antihypertensive Survival Evaluation in Japan (CASE-J) trial. The CASE-J trial ${ }^{2}$ was designed to compare the long-term effects of the angiotensin II receptor blocker candesartan and the calcium channel blocker amlodipine on the incidence of cardiovascular events, represented as a composite of sudden death and cerebrovascular, cardiac, renal and vascular events in high-risk Japanese hypertensive patients. The main findings of this study showed that candesartan-based and amlodipinebased regimens did not show statistical differences in terms of the primary cardiovascular end point, whereas candesartan prevented new-onset diabetes more effectively than amlodipine.

In the current sub-analysis, the authors examined the influence of pre-existing diabetes on cardiovascular morbidity and mortality using a multivariate Cox regression model. ${ }^{1}$ In this study, pre-existing diabetes greatly increased the cardiovascular mortality and morbidity in both groups, but all-cause mortality was significantly higher with amlodipine than with candesartan among patients with body mass index $\geqslant 27.5 \mathrm{~kg} \mathrm{~m}^{-2}$ (hazard ratio $0.32 ; P=0.009)$. Moreover, new-onset diabetes occurred significantly less frequently with candesartan than with amlodipine (hazard ratio $0.66 ; P=0.043$ ). Notably, the increase in new-onset diabetes was dependent on body mass index among patients receiving amlodipine, but this was not the case for the subjects treated with candesartan.

The most important aim in the hypertensive population is to attain blood pressure goals. This can be obtained with the help of different antihypertensive agents, such as renin-angiotensin system inhibitors, calcium channel blockers, diuretics, beta-blockers or, more frequently, a combination of some of these. ${ }^{3}$ However, available evidence shows that despite all the antihypertensive drug classes achieving similar blood pressure reductions, not all of them have the same impact on cardiovascular morbidity and mortality. ${ }^{4}$ Patients with obesity, metabolic syndrome or impaired glucose tolerance have an increased risk of type 2 diabetes mellitus and cardiovascular disease. ${ }^{5}$ Therefore, interventions that might reduce the development of new-onset diabetes would likely decrease cardiovascular outcomes during follow-up. ${ }^{5}$ The Nateglinide and Valsartan in Impaired
Glucose Tolerance Outcomes Research (NAVIGATOR) trial $^{6}$ compared in more than 9000 patients with impaired glucose tolerance the effects of adding valsartan (up to $160 \mathrm{mg}$ daily) vs. placebo on the development of diabetes. Although the addition of valsartan did not result in a reduction of cardiovascular events, a relative reduction of $14 \%$ in the incidence of diabetes was observed. These data demonstrate the beneficial effect of the angiotensin-receptor blocker-based therapy in the prevention of new cases of diabetes.

But what happens with hypertensive patients that are obese or diabetics? Nakao et al. ${ }^{1}$ showed that all-cause mortality was significantly higher with amlodipine than with candesartan among patients with body mass index $\geqslant 27.5 \mathrm{~kg} \mathrm{~m}^{-2}$. These results are not surprising. Cardiovascular disease is a continuum, from risk factors and subclinical organ damage to clinical cardiovascular conditions. Those antihypertensive agents that effectively reduce organ damage will delay the development of cardiovascular outcomes. Previous studies have shown the benefits of a candesartan-based regimen effectively regressing left ventricular hypertrophy detected
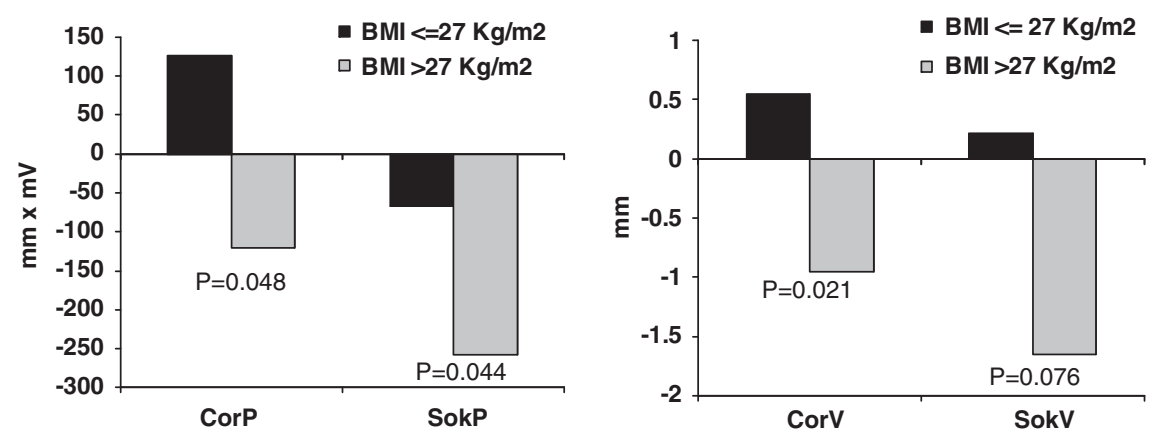

Figure 1 Effects of a candesartan-based regimen on electrocardiographic left ventricular hypertrophy according to body mass index in male patients (adapted from Barrios et al. ${ }^{9}$ ). Abbreviations: BMI, body mass index; CorP, Cornell product; CorV, Cornell voltage index; SokP, Sokolow-Lyon product; SokV, Sokolow-Lyon voltage index. 
either by echocardiogram or by electrocardiogram in diabetic populations in clinical practice. ${ }^{7,8}$ Moreover, despite electrocardiographic left ventricular hypertrophy being more common in diabetics, hypertensive patients with diabetes achieved a higher reduction in left ventricular hypertrophy prevalence with a candesartan-based regimen than non-diabetics. ${ }^{8}$ A more recent analysis of these data was focused on the effects of a 12-month candesartan-based regimen on electrocardiographic left ventricular hypertrophy according to body mass index. ${ }^{9}$ In this analysis two groups of patients were studied: those with body mass index $\leqslant 27 \mathrm{~kg} \mathrm{~m}^{-2}$ and those with body mass index $>27 \mathrm{~kg} \mathrm{~m}^{-2}$. Although at baseline blood pressure values and electrocardiographic left ventricular hypertrophy prevalence were similar in the two groups, at the end of the study the reduction in Cornell voltage index was significantly higher in patients with higher body mass index $(-0.30$ vs. $-1.49 \mathrm{~mm}, P=0.021)$. There was also observed a trend for a higher reduction in Cornell product criterion in the subgroup of overweight-obese patients than in normal-weight subjects ( -6.66 vs. $-152.93 \mathrm{~mm} \mathrm{mV}, \quad P=0.078)$. Interestingly, these results were more evident in the male gender (Figure 1).

All these data emphasize the importance of the treatment with candesartan in patients with hypertension and metabolic disorders, not only because of its efficacy in decreasing the blood pressure and mortality rates in patients with diabetes or obesity, but also because of the potential for prevention of new-onset diabetes.

\section{Vivencio Barrios ${ }^{1}$, Carlos Escobar ${ }^{2}$ and} Alberto Calderon ${ }^{3}$

${ }^{1}$ Department of Cardiology, Hospital Ramón y Cajal, Madrid, Spain; ${ }^{2}$ Department of Cardiology, Hospital Infanta Sofia, San Sebastian de los Reyes, Madrid, Spain and Primary Care Center, Rosa de Luxemburgo, San Sebastián de los Reyes, Madrid, Spain

E-mail:vbarriosa@meditex.esor vbarrios.hrc@salud.madrid.org

1 Nakao K, Hirata M, Oba K, Yasuno S, Ueshima K, Fujimoto A, Ogihara T, Saruta T. Role of diabetes and obesity in outcomes of the candesartan antihypertensive survival evaluation in Japan (CASE-J) trial. Hypertens Res 2010; 33: 600-606.

2 Ogihara T, Nakao K, Fukui T, Fukiyama K, Ueshima K, Oba K, Sato T, Saruta T, Candesartan Antihypertensive Survival Evaluation in Japan Trial Group. Effects of candesartan compared with amlodipine in hypertensive patients with high cardiovascular risks: candesartan antihypertensive survival evaluation in Japan trial. Hypertension 2008; 51: 393-398.
3 Escobar C, Barrios V. Combined therapy in the treatment of hypertension. Fundam Clin Pharmacol 2010; 24: 3-8.

4 Jamerson K, Weber MA, Bakris GL, Dahlöf B, Pitt B, Shi V, Hester A, Gupte J, Gatlin M, Velazquez EJ, ACCOMPLISH Trial Investigators. Benazepril plus amlodipine or hydrochlorothiazide for hypertension in high-risk patients. N Engl J Med 2008; 359: 2417-2428.

5 Nathan DM, Davidson MB, DeFronzo RA, Heine RJ, Henry RR, Pratley R, Zinman B, American Diabetes Association. Impaired fasting glucose and impaired glucose tolerance: implications for care. Diabetes Care 2007; 30: 753-759.

6 NAVIGATOR Study GroupMcMurray JJ, Holman RR, Haffner SM, Bethel MA, Holzhauer B, Hua TA, Belenkov Y, Boolell M, Buse JB, Buckley BM, Chacra AR, Chiang FT, Charbonnel B, Chow CC, Davies MJ, Deedwania P, Diem P, Einhorn D, Fonseca V, Fulcher GR, Gaciong Z, Gaztambide S, Giles T, Horton E, Ilkova H, Jenssen T, Kahn SE, Krum H, Laakso M, Leiter LA, Levitt NS, Mareev V, Martinez F, Masson C, Mazzone T, Meaney E, Nesto R, Pan C, Prager R, Raptis SA, Rutten GE, Sandstroem H, Schaper F, Scheen A, Schmitz O, Sinay I, Soska V, Stender S, Tamás G, Tognoni G, Tuomilehto J, Villamil AS, Vozár J, Califf RM. Effect of valsartan on the incidence of diabetes and cardiovascular events. N Engl J Med 2010; 362: 1477-1490.

7 Barrios V, Escobar C, Calderón A, Vegazo O, Fernandez $R$, Asín $\mathrm{E}$. Regression of left ventricular hypertrophy in diabetics by a candesartan-based regimen in clinical practice. Diabetes Res Clin Pract 2007; 77: 492-493.

8 Barrios V, Escobar C, Calderon A, Echarri R, Barrios S, Navarro-Cid J. Electrocardiographic left ventricular hypertrophy regression induced by an angiotensin receptor blocker-based regimen in hypertensive patients with diabetes: data from the SARA study. J Renin Angiotensin Aldosterone Syst 2009; 10: 168-173.

9 Barrios V, Escobar C, Calderon A, Barrios S, Echarri R, Navarro-Cid J. Electrocardiographic left ventricular hypertrophy regression induced by an angiotensin receptor blocker-based regimen in hypertensive patients according to body mass index. Data from the SARA study. Presented at the World Congress of Cardiology, Beijing, China, 16-19 June 2010. 